\title{
Doing Syringe Exchange: Organizational Transformation and Volunteer Commitment
}

\author{
Margaret S. Kelley \\ University of Oklahoma
}

Howard Lune
William Paterson University
Sheigla Murphy
Institute for Scientific Analysis

The authors examine the organizational transformation of Prevention Point, the San Francisco-based syringe exchange program. Their purposes are to explore the processes of organizational change, focus on the impact of formalization on members and organizational goals, and contextualize these in light of belonging to an underground organization. They highlight the volunteers' motivation and commitment, and their responses to the organizational changes. Drawing on qualitative interviews with 56 service providers, conducted from 1993 to 1995, the authors document the changes in the organization and the members' perceptions of it as it moved from an illegal, deviant group to a socially sanctioned service organization. This transition is shown to have ultimately undermined much of the basis for volunteer commitment, reinforcing the shift in responsibility from the membership to a new management structure. These findings have implications for the larger problem of maintaining volunteer engagement in volunteer work.

Keywords: illicit drug use; volunteerism; harm reduction; quantitative and qualitative

It has been more than 75 years since Max Weber (1922/1978) identified the hazards of "routinization" faced by ideologically minded organizations as they seek to supplant the vision of charismatic leaders with enduring structures and procedures. With a few modifications, Weber's general schema has continued to inform the analysis of voluntary service organizations in

Note: This was a National Institute on Drug Abuse-funded study, “AIDS Prevention: An Ethnography of Needle Exchange" (RO1 DA08322), Sheigla Murphy as principal investigator, The Institute for Scientific Analysis. We thank the anonymous reviewers for their suggestions on improvements to the article.

Nonprofit and Voluntary Sector Quarterly, vol. 34, no. 3, September 2005 362-386 DOI: $10.1177 / 0899764005275568$

(C) 2005 Association for Research on Nonprofit Organizations and Voluntary Action 
transition (Torres, McIntosh, \& Zey, 1991). In particular, numerous studies of organizations with political and social-change goals in the field of public health, such as feminist health clinics, have found organizers struggling with the conflict between organizational imperatives and cultural values (Lebon, 1996; Morgen, 1986; Thomas, 1999). For scholars of social movements, the transition of many activist organizations into "professional" social agencies has been hypothesized to follow a path roughly along the lines of Roberto Michels's "iron law of oligarchy" (Staggenborg, 1988; Zald \& McCarthy, 1987), in which leadership becomes an end in itself, supplanting organizational goals. Implicit in organizational routinization, with or without oligarchy, are the related processes of the formalization of organizational structure, the professionalization of organizational processes, and the increasing complexity of the internal division of labor (Rucht, 1999). Without deliberate efforts to the contrary, structures tend to become more rigid and member relations more formal as groups reorganize for long-term stability (Rothschild-Whitt, 1979). To Michels's analysis of internal power struggles and the desire for success, organizational theorists have added institutional, economic, and cultural constraints and incentives that reshape organizations during periods of transition (DiMaggio \& Powell, 1983; Jenkins, 1998; Jepperson, 1991).

Consistent with these findings, studies of the transition of illegal service providers into "legal agencies" (methadone, abortion services, aid to illegal aliens, etc.) have found that as the services emerge to meet client needs, structural changes and conflicts arise around the participation of volunteers and the internal organization of labor (Des Jarlais, Paone, Friedman, Peyser, \& Newman, 1995; Kelley, 1994; Kochems et al., 1996). Underground organizations that have demonstrated their effectiveness and won public support often tend to formalize their core functions, seek public funding and the stabilization of space, followed by the hiring of staff and, eventually, the transition to professional management (Des Jarlais et al., 1995). Within the domain of HIV / AIDS services and advocacy, the combined influence of preexisting structures of the public health field and the political needs of government agencies have led many community-based organizations to emphasize service provision at the expense of political participation (Brown, 1997; Cain, 1995; Lune \& Oberstein, 2001), although several other patterns of organizational transition have also been identified (Chambre, 1997).

In this article, we examine the role of volunteers and volunteer commitment in relation to the organizational transition from underground to legitimate modes of operation. Our work is guided by the standard Weberian model of professionalization, and its offshoots, and our interest in how they apply to contemporary organizational transitions. Using qualitative data, we seek to explain the processes and motivations underlying both those elements that conform to expectations and those that do not. More important, we use this model to demonstrate the effects of organizational transition on the experience of volunteers and the breakdown of volunteer commitment in a private, nonprofit organization operating in the public sphere. We do so through a case 
study of a San Francisco-based syringe-exchange program, Prevention Point, which underwent such a change in form from its founding as an underground group in the late 1980s through its reorganization into a legitimate, socially sanctioned organization in the 1990s. Because the changes in the organization's legal status coincided with our data collection (1993-1995), we were able to study the beginnings of Prevention Point's transformation from an illegal, underground operation to a publicly supported agency, with particular attention to the shifting relationship between staff and volunteers, and the reconceptualization of leadership functions during the years in which Prevention Point moved from its underground existence to a status best described as quasi-legal. ${ }^{1}$ That is to say, after transition they operated in an environment of tolerance but did not have the security of full legal status, which we describe in detail below.

Our primary concern is with the changing role of the volunteer in the context of an organization that espoused a philosophy of participant management. In addition to collecting basic organizational data, therefore, we sought the volunteer providers' evaluations of the program and its transition. Our results provide a rich account of the volunteers' motivation and commitment to the organization. We conclude with a consideration of the impact of the changing organizational structure on organizational effectiveness. Several organizational factors that characterized Prevention Point were strongly affected by the nature of the transformation. These included a participant management style, their deviant status, a complex distribution of rewards among volunteers, the members' commitment to the interests of their constituents, and the organization's unifying ideology of harm reduction. As the organization adapted its forms and practices to accommodate the external pressures that accompanied public support, it was perceived to have reduced its emotional commitment to its constituents, undermining both its participant management style and its ideological stance.

\section{METHOD}

We conducted a 3-year process evaluation of Prevention Point beginning at the time of its transition from underground to quasi-legal operations (Murphy, Wenger, \& Kelley, 1996). We used multiple data sources to triangulate on the key variables. Data collection included participant observation, indepth life history interviews, and a closed-ended quantitative instrument. Data collection was completed in 1995 with a total of 244 exchange participants (clients of the syringe-exchange program) recruited from eight syringeexchange sites, many of whom exchanged needles for other users unable or unwilling to visit the exchange (Kelley, Murphy, \& Lune, 2001; Murphy, Kelley, \& Lune, 2004). Data collection also included interviews with 56 volunteer service providers, which represented the total population of providers involved at the eight data collection sites during the time of our study. The 
interviews with the providers were of shorter duration and focused on eliciting information about their motivations, tasks, and overall volunteer experience. These interviews took place during the course of data collection and included both original founding members and new members as they joined the organization. We did not track movement in and out of the organization, and some members likely left after completing interviews. The life history interviews, lasting about 2 hours each, were transcribed and entered into Ethnograph 5.0, a qualitative software program, for textual analysis. Basic demographic information was collected through short-answer questions and analyzed in SPSS 10.0. The participant observation portion of the study lasted throughout the 3 years of data collection. Interviewees were identified during observation. Project staff spent approximately 10 hours per week in the field in addition to time spent in interviews. ${ }^{2}$

When revisiting some key issues while writing this article, several of the original founders of Prevention Point were contacted to revisit historical issues and to compare the operations of Prevention Point before and after its transition. These data allow us to ask follow-up questions concerning the outcomes of questions that had been raised during our initial interviews. Because two of the individuals who are quoted in this article could not be matched with their original, anonymous interviews, they have been given new pseudonyms.

As part of its change in status from quasi-legal to legal, Prevention Point was taken over in 2001 by the San Francisco AIDS Foundation under the name San Francisco's HIV Prevention Project. The present analysis concentrates on the early, illegal and quasi-legal underground days of Prevention Point, and the period of transition between the two. In both the new and old forms, the leadership of Prevention Point were fully supportive of our study.

We begin with a description and analysis of Prevention Point's transformation, followed by an analysis of the volunteers, focusing on their motivations and commitment. We then turn to the volunteers' expectations and experiences of the organizational transition. Throughout, we quote extensively from the provider interviews in order to provide rich description of the events under study. Although the more precise term "syringe exchange" has been widely adopted in recent years, most of our informants were using the phrase "needle exchange" (or NEX) at the time of our data collection. In this article, the two terms are treated as interchangeable. After examining the organization and organizational identity, we describe the sample and their interests.

\section{THE ORGANIZATION}

Prevention Point's founders, attempting to stem the tide of HIV infection among injecting drug users (IDUs), believed it was best to forge ahead with their plans and face the political and community backlash later. Most of the 
original exchangers worked in AIDS-related research or health or social service agencies and were mourning the loss of friends and clients from HIVrelated illnesses. They were unwilling to wait for permission (legal sanction) while watching firsthand the increasing numbers of IDU-related deaths (Moore \& Wenger, 1995). In their search for allies, they looked to the drug users themselves rather than the field of health service providers, the latter of whom would have had more difficulty with the inherent illegality of the service. This initial decision, to connect with their grassroots constituency in preference to their institutional environment, established the trajectory of many of the organizational decisions to follow (Lune \& Oberstein, 2001). From the beginning, Prevention Point was an instrumental political organization with the long-term goal of changing society's response to IDUs, in the model of a traditional social movement organization (Booth, Babchuk, \& Knox, 1968).

In the 16 months prior to the first night of the exchange, the founding mothers and fathers designed San Francisco's syringe-exchange program by consulting with IDUs, community activists, and select health professionals. First, they went to their potential clients and asked them what they needed and how, when, and where to provide it. Second, they invited input from other members of the community, including activists and political leaders. To encourage attendance and grassroots participation, they served food at their meetings, which proved to be a successful strategy.

Prevention Point began illegal distribution of syringes and other harmreduction materials in San Francisco on November 2, 1988 (Lane, Lurie, Bowser, Kahn, \& Chen, 2000; Moore \& Wenger, 1995). ${ }^{3}$ On the first night, they exchanged 13 clean needles for used ones. Since that night, the numbers of syringes exchanged increased exponentially. During the first 6 months of the program's operation, 4,500 needles were exchanged. From June 1989 to May 1990 they exchanged 116,000 syringes. For the same time period in 1990-1991 they exchanged 298,000 syringes.

\section{THE ORGANIZATIONAL IDENTITY OF A DEVIANT ORGANIZATION}

Prevention Point's organizers were committed to a philosophy of harm reduction. Harm reduction, as an approach to the drug problem, focuses on reducing or eliminating drug-related harm among active drug users rather than focusing entirely on getting drug users to stop using (Des Jarlais, 1995; Inciardi \& Harrison, 2000; Kelley et al., 2001; Rosenbaum, Washburn, Knight, Kelley, \& Irwin, 1996). A 1995 national survey of syringe-exchange programs identified a broad range of harm-reduction services provided by the 55 exchange groups then operating, including condom distribution, HIV counseling and testing, testing and treatment for tuberculosis, and basic health care, in addition to the distribution of syringes, cotton balls, and bottle caps ("Syringe Exchange Programs," 1995). At the time of data collection, Prevention Point sites provided all of these HIV-related services as well as 
information on safer sex and injection practices and referrals on request to drug treatment programs and health care and social service agencies. During this period, Prevention Point operated eight sessions Monday through Friday. ${ }^{4}$

While still in the planning stages, the founders began to recruit friends and other volunteers to develop the exchange. Consistent with prior instances of "high risk" activism (Della Porta, 1988; McAdam, 1982), they drew upon their personal networks within the HIV / AIDS world and the social movement sector. "It was an interesting group of folk," Shirley, an original member of Prevention Point, recently recalled. They were "smart, feisty, irreverent, politically savvy, dedicated, many were experienced at civil disobedience-type actions on other issues, anti-war, anti-nuke, civil rights, that sort of thing." At that time, California's prescription and paraphernalia laws restricted both the distribution and possession of syringes. The volunteers enacted their exchange as a form of civil disobedience. They believed that despite its illegality, the exchange of clean needles for dirty ones was imperative to stem the spread of HIV among IDUs. This belief, and the willingness to violate the law for their beliefs, placed a firm barrier between the volunteers and the rest of the public health sector within which many of them worked at their day jobs.

During the group's illegal phase, organizers took pains to ensure that there was both ideological and practical commitment from all participants on any significant decision. Dale, also an early member of the organization, said,

We followed a consensus decision-making process. This meant that there was no voting with a majority winning and a disaffected minority with their nose out of joint. Nothing was decided until we all agreed on it. It means arguments until two in the morning sometimes. But it also means that when you are done everyone feels satisfied with the result and is committed to it. It worked well for us when we were a small group of underground activists but was abandoned in later years as we got much larger, much to the distress of some of the original crew.

\section{RELATIONS WITH THE PUBLIC HEALTH SECTOR}

Formal and informal relations with the public health sector proved important in the organization's development. Prevention Point's founders were researchers and public health employees at various community health projects, tracking the incidence of HIV / AIDS, providing testing and counseling, and teaching about safer sex. But according to one of the founders, they had become frustrated with their inability to be more proactive. Shirley said,

When Diane Feinstein was mayor of San Francisco, she had been approached with the idea of a syringe exchange to slow down the spread 
of HIV through the needle-using population, and she thought that was a terrible idea and said so vehemently. So the mainstream leaders were afraid to go there. However, the front-line workers were a feisty bunch and feeling increasingly desperate to do something more effective. Then we heard about someone in Tacoma starting his street-based exchange and that pretty much precipitated our decision to act.

Despite close ties to the formal institutions of public health, the founders emphasized their connectedness with their community of need. The organization operated in a manner that would bring them closer to the injecting drug users whom they were attempting to reach, and hide them from the awareness of their colleagues in social services, health care, and HIV / AIDS research. For obvious reasons, they also sought to avoid contact with law enforcement agencies.

Informants described the elaborate precautions they took to disguise their activities, including hiding the sterile syringes in a baby buggy while walking their distribution route. They initially worked only at night, partly to accommodate the volunteers' day jobs but also to take advantage of "the cover of darkness," in the words of one founder. Yet, even during the organization's illegal phase, the underground volunteers had faced a minimum of interference. In contrast to the experiences of underground exchange programs in New York City and elsewhere (Broadhead, Van Hulst, \& Heckathorn, 1999; Kochems et al., 1996; Lune, 2002), community and political leaders in San Francisco generally chose to turn a blind eye to the community group's efforts.

In time, the mobile baby buggy became a routine part of the world of IDUs, recognized by both users and the police. Instead of hiding their actions, the undercover nature of their work provided police and health officials with the opportunity to quietly observe them in the community while maintaining plausible deniability. This "don't ask, don't tell" approach served to smooth the transition from underground to legitimate operations. The willingness and ability of the participant population, including many IDUs, to collaborate in keeping a low profile alleviated fears that the exchange would disrupt the community. It also helped to solidify the sense that the group was more "embedded" in the local community than in the domain of health and social services (Lune \& Oberstein, 2001). One volunteer, Yvonne, a 51-year-old White woman, described her recognition of the users' acumen in this regard:

We're totally outside the criminal justice eyes, outside the system completely, by choice, so, what is there to kind of anchor us in any kind of order, you know? I was so surprised the first time, how orderly everything was. It's almost like the clients keep it orderly. It's like they want this badly enough that they're going to keep it orderly. 


\section{GROWTH AND EXPANSION}

Prevention Point expanded during its illegal phase (1988-1993), adding several stationary sites to their mobile buggy distribution. Greater volunteer support and the tacit, if unspoken, approval of city officials allowed them to increase their hours and their street presence. The rapid expansion of Prevention Point services and the growing recognition of the extent of community needs led Mayor Frank Jordan and San Francisco's Board of Supervisors to declare a state of medical emergency in March 1993, allowing the city to circumvent state law on behalf of the group. It also allowed San Francisco's Department of Public Health to fund Prevention Point and enabled syringeexchange volunteers and staff to exchange syringes openly. The state of medical emergency did not minimize the illegality of possession of syringes, but it did allow Prevention Point to operate without fear of prosecution. From that time until 2001, when the state of California altered its paraphernalia laws to allow syringe exchange, the board had to revalidate the medical emergency ordinance every 2 weeks in order to protect Prevention Point's quasi-legal status. From 1993 onward, the program was able to operate in full daylight, figuratively and literally, to seek public funding, and to actively recruit new volunteers. This period of growth and outreach greatly expanded the organization's effectiveness, but it also led to a considerable amount of selfreflection and reorganization.

\section{Legal Status and Organizational Change}

Quasi-legal status allowed Prevention Point to form connections with other health organizations and to increase the number of services they could offer. At the same time, because the emergency ordinance referred only to syringe exchange, the group had to restrict its work only to those activities that were either legal or protected, and only in the prescribed manner. Like most other syringe-exchange programs, Prevention Point participants exchanged on a one-for-one basis (used for sterile) in order to reduce the number of contaminated syringes in circulation and appease opponents. Needles themselves have been assigned meaning as risky objects (Strike, Myers, \& Millson, 2002). But Prevention Point balanced these concerns by defining needles as a necessarily risky object of prevention and were then able to provide additional prevention information on safer sex and injection practices, referrals on request to drug treatment programs, health care and social service agencies, and tangible items such as bleach, alcohol wipes, cotton balls, and condoms. They fostered their contacts within the public health sector as well as among other HIV/ AIDS groups and advocates for changes in drug policy and law, helping to bridge the gap between the community in which they worked and the rest of the health and services domain. This instrumental organization, both deviant and political, moved forward with the original goal of practicing harm reduction for IDUs in the San Francisco area. 


\section{THE PROVIDERS}

The volunteers were witnesses to a long process of organizational change. The change did not happen overnight, but rather spanned a number of years. Our interviews with providers capture this process but do not provide clearcut categories of before-and-after experiences of the transition. Instead, most informants tended to make explicit comparisons between conditions at the time of the interview and the conditions under which they had begun their work at Prevention Point. As shown in Table 1, there was a reasonable amount of demographic diversity among those who volunteered at Prevention Point during the period of study, though a few trends are discernible. Women outnumbered men by almost $50 \%$. Most volunteer providers were White. The average age was 32.4 years, ranging from 16 to 64 . Less than half of the providers were heterosexual $(44.6 \%), 16$ providers were lesbian or gay $(28.6 \%)$, and 15 self-identified as bisexual (26.8\%). The majority of the providers had no religious affiliation (60.7\%). In many respects, they resembled the distribution of demographics previously found in other HIV / AIDS activist organizations (Elbaz, 1992).

Several providers combined their employment with their syringeexchange volunteer work because they were paid as community health outreach workers and would make contacts during their syringe-exchange volunteer shifts. Other providers had other politically oriented kinds of employment, such as advocating for women's needs or community organizing. At least three providers were in school full-time, whereas others were in school part-time.

The providers were relatively well educated. As shown in Table 1, The vast majority had at least some college education. The volunteer base also included both former or current drug injectors and those who had no personal injecting experience. Forty-two of the providers had never injected drugs. One was an active user and there were 12 former IDUs among our respondents $(21.8 \%)$. Among those who were not users, there were mixed feelings concerning the inclusion of active drug injectors in organizational management decisions. Sixteen of those interviewed had been with the organization since its early days, for 10 or more years.

\section{Reasons for Volunteering}

Why did the volunteers come to Prevention Point? The most common reasons for volunteering were the desire to participate in AIDS politics, program requirements (usually a class project), and relationships with other volunteers or users. These reasons were not mutually exclusive, and all fostered a sense of community with other volunteers and exchange participants. The founders had all been friends or colleagues before the launch of Prevention Point. Many recruits were personal contacts from other HIV / AIDS organizations. Underlying each of these rationales, for those who stayed on, was an ideological 
Table 1. Sociodemographic Characteristics of Providers by Gender (number)

\begin{tabular}{|c|c|c|c|}
\hline & $\operatorname{Men}(\mathrm{n}=21)$ & Women $(\mathrm{n}=35)$ & Total $(\mathrm{n}=56)$ \\
\hline \multicolumn{4}{|l|}{ Age } \\
\hline 24 or younger & 4 & 7 & 11 \\
\hline $25-29$ & 5 & 5 & 10 \\
\hline $30-39$ & 6 & 14 & 20 \\
\hline 40 or older & 6 & 8 & 14 \\
\hline \multicolumn{4}{|l|}{ Ethnicity } \\
\hline White & 12 & 26 & 38 \\
\hline African American & 4 & 4 & 8 \\
\hline Latino & 4 & 3 & 7 \\
\hline Pacific Islander & 1 & 1 & 2 \\
\hline \multicolumn{4}{|l|}{ Sexual orientation } \\
\hline Lesbian or gay & 4 & 12 & 16 \\
\hline Bisexual & 4 & 11 & 15 \\
\hline Heterosexual & 13 & 12 & 25 \\
\hline \multicolumn{4}{|l|}{ Level of education } \\
\hline Less than high school & 2 & 0 & 2 \\
\hline High school & 3 & 1 & 4 \\
\hline Some college or trade & 6 & 4 & 10 \\
\hline College & 5 & 18 & 23 \\
\hline More than college & 5 & 12 & 17 \\
\hline \multicolumn{4}{|l|}{ Injecting drug user status } \\
\hline Never & 15 & 27 & 42 \\
\hline Active user & 0 & 1 & 1 \\
\hline Ex-user & 6 & 6 & 12 \\
\hline \multicolumn{4}{|c|}{ Length of time with program } \\
\hline Less than 1 year & 2 & 5 & 7 \\
\hline $1-3$ years & 6 & 8 & 14 \\
\hline $4-6$ years & 6 & 8 & 14 \\
\hline $7-10$ years & 3 & 2 & 5 \\
\hline More than 10 years & 4 & 12 & 16 \\
\hline
\end{tabular}

alignment or emotional commitment to the group and its mission, centered on the philosophy of harm reduction. The volunteers expressed solidarity with the program participants, the IDUs, and defined their activities in opposition to current laws and policies. These reasons are consistent with findings from other forms of collective action in which personal networks have been identified as key links to high-risk volunteering (Gould, 1991; McAdam, 1982). Although true of formal organizations, it is even more important for a deviant, in this case illegal, organization. The dense political and activist networks of San Francisco assisted in maintaining membership. Once involved with the exchange, the rewards and improved well-being kept them there (Thoits \& Hewitt, 2001). Given the organization's early commitment to participatory management, the volunteers' sense of ideological alignment with the group should not be surprising. They were creating a new organization whose 
purpose was to fulfill their own sense of mission. The later volunteers also self-selected based on their predefined agreement with the organization, among other factors.

\section{ORGANIZATIONAL CULTURE}

The volunteers on the street worked relatively independently, personally providing the materials and services to their program participants. The organization provided the supplies and the location, but the volunteers were clearly the ones who had the direct impact on people's lives. The nature of the work, the autonomy, and the casual division of labor encouraged the sense among volunteers that they were an integral part of a needle-exchange community. Being "on the street" was a positive thing, tinged with danger.

Even among those who joined for ostensibly utilitarian goals, such as class projects, the sense of community often dominated. For example, Yvonne joined the syringe exchange when she was fulfilling an assignment to become involved in an activist organization. Although she joined because of a program requirement, she recalled how she enjoyed the work and how she got "hooked":

Oh, it's very demanding. The interesting thing is, it is very important to me. You know, I went to the needle exchange conference ... and I heard some of those speakers, and I was moved. Right now I'm applying for jobs and I'm thinking I'm going to have to leave, and every application I send someplace away from here, I think, now let's see, what is their needle exchange? Will I have to start it myself? Does this state allow needle exchange? I can't explain it but I really am hooked in.

Yvonne expressed ideological commitment to the organization and to Prevention Point's philosophy and agenda:

The whole philosophy of harm reduction, I really buy that. I mean, let's face it, other kinds of drug programs and things, if they work at all, work on a very small percentage of people, and, I really think we have to think of other things.

Similarly, Cheryl, a 20-year-old White woman, highlighting the harm-reduction goals of the organization, remarked that "needle exchange isn't about the drug use at all, really. It's just about the prevention of AIDS and stopping the spread of the AIDS epidemic and that's a really important thing for me to remember." Multiple memberships in social change organizations are not uncommon among politically motivated volunteers (Carroll \& Ratner, 1996). Several of the providers for whom this was the case mentioned that this particular kind of work was "easier" than their other political work. It was not like a 
job at all. They enjoyed the break from intense political work, but also enjoyed the politics of the exchange and the fact that they had fun while working a site.

Many mentioned the challenge of breaking the law as an attractive element of the experience. With their clients on one side of the law and the city and police on the other, the illegal nature of the work strengthened their identification with the IDUs whom the program served. Through Prevention Point, volunteers were able to engage in acts of civil disobedience through which there was some reasonable possibility of affecting social change on behalf of a marginal community. Ruth, a 32-year-old White woman, commented on the deviant motivation for volunteering and how that changed over time:

I kind of like the fact that it was kind of illegal, it makes me feel a little daring. So that fills my need of being like on the cutting edge or something. I've definitely noticed that that's something I kind of feel now, like "ha-ha," doing something in defiance. But originally I was just interested because I thought, God, that's such a needed service. I do get a vicarious pleasure out of it, feel like I'm being really daring. So it's like "oh, too bad, it's funded by the city now"; you can't be super-daring.

The desire to challenge, or break, the law was coupled with the idea that their cause was just. The volunteers undertook personal risks with little chance for personal rewards, beyond the hope of fulfilling the organization's mission. Their service, however, was not to an organization but to a community of need. By far the most frequently mentioned reason for volunteering with Prevention Point was the social impact of the work they did while at the exchange.

The personal well-being as a result of volunteering kept many volunteers engaged, though respondents invoked a complex distribution of personal rewards when discussing their relationship to the work. Clay, a 27-year-old White man, when asked what kept him volunteering at syringe exchange, responded in a manner that emphasized his connection to the clients, the sense of giving to the community, and the favorable cost-benefit ratio. He said,

Once you're out there, you know, you've got your schedule and your time, you know the people you're volunteering with, the clients become familiar, it's really not that difficult distributing things. And, it does a world of good for people. You can see that. And people will tell you so, in the exchange line. And, it's a couple hours a week. It's really not that difficult to just show up, pass out bleach, and go home.

\section{BEING AND DOING}

Providers often emphasized that they identified with the mission of the organization, that this work was part of their social identity. Although political and social concerns motivated the volunteers to support syringe exchange, 
Table 2. Provider Site Tasks by Gender (number)

\begin{tabular}{lccc}
\hline & Men $(\mathrm{n}=21)$ & Women $(\mathrm{n}=35)$ & Total $(\mathrm{n}=56)$ \\
\hline Most favorite task & 6 & 9 & 15 \\
$\quad$ Giving out syringes & 3 & 9 & 12 \\
$\quad$ Counting syringes & 5 & 6 & 11 \\
$\quad$ Giving out condoms, etc. & 9 & 13 & 22 \\
Least favorite task & 5 & 5 & 10 \\
$\quad$ Giving out condoms, etc. & 3 & 5 & 8 \\
Like all tasks & & & \\
$\quad$ Counting syringes & 8 & 9 & 12 \\
Primary task & 3 & 5 & 9 \\
$\quad$ Giving out condoms, etc. & 4 & 9 & \\
$\quad$ Counting syringes & & & \\
$\quad$ Giving out syringes & & & \\
\hline
\end{tabular}

when talking about the work, respondents overwhelmingly reported that they enjoyed direct contact with the exchange program participants. As shown in Table 2, the most frequently mentioned favorite task while working at an exchange site was handing out syringes, followed by counting syringes and distributing condoms and other supplies. Volunteers wanted to distribute the needles because they perceived that as "the whole point" of why they were there. This action defined who they were as volunteers.

For many, their volunteer work was materially consistent with their paid jobs, but qualitatively different in meaning. As noted above, the majority of the providers were employed in either HIV/AIDS or other health-related fields, including health research organizations. Toshi, a 32-year-old White woman, worked as a medical assistant for a general surgeon who worked with HIV-positive clients. Her efforts with syringe exchange gave her a personal involvement in an HIV / AIDS intervention that was motivated by her professional work.

It makes me feel very practical about it, I mean I don't really get into these sort of moral arguments with people about should it or shouldn't it be done, because I can see this is what happens when people get infected and it's a heavy thing. So I guess that, in a way, has affected my perspective on things.

From the start, the long-term, pragmatic goal of the syringe-exchange program was to impede the transmission of HIV. In the short run, however, the original volunteers sought to distribute sterile needles and to create a framework for the legal operation of syringe exchange. This sense of mission entailed a philosophical stance, a public health perspective, and a set of assumptions about the place of syringe-exchange advocates in the system of 
relations linking IDUs to policy makers. As they began to progress toward their goals, the organizers and operators of syringe exchange found their relations with program participants, with the organization, and with city government shifting in ways that they had not always anticipated. Without significant changes in their day-to-day tasks, other than the infusion of public funding, the operators of the syringe exchange found their social roles in flux. Internal changes in the nature of the work altered its meaning for many volunteers.

\section{VOLUNTEER REACTIONS TO ORGANIZATIONAL TRANSITION}

Volunteers responded in different ways to the organizational changes. The tasks had remained more or less the same for most of the volunteers. Only the "upper-level" volunteers found the transition to significantly change day-today existence, with more emphasis placed on networking and paperwork rather than daily contact with clients. Gradually, however, as the organizational structure and decision processes began to change, volunteers found their sense of place in the group also changing. Most notably, and somewhat predictably, the senior volunteers began to really become "the management" while many of the service providers found themselves less involved in decision making. Among other changes, this led to circumstances in which "staff" questioned the wisdom of decisions that had been made without their input. In general, volunteers were pleased with changes that affected what they did but displeased with changes in how it was done.

\section{TRANSITION EXPECTATIONS}

Volunteers described the anticipated changes as individual pragmatic improvements, not as a sweeping reinterpretation of the organization's form of work. They imagined the changes being introduced within the context of the participant management style of organization. That is, individual providers understood they had a role to play in the decision making of the group, and they expected to participate in implementing these changes. They were looking forward to the practical benefits of professionalization without having fully considered the impact of this transition on the processes that they had chosen to put in place. They mostly wanted to be more effective at doing what they were already doing.

Prevention Point's new status promised a number of changes that the volunteer service providers hoped would improve the effectiveness of the organization. For starters, they wanted a regular and uninterrupted source of supplies. Those volunteers who had been with the organization from the beginning remembered running out of needles and having to turn away potential exchange participants. Next, providers hoped to see the further 
development of ancillary services such as on-site medical care and referrals to available treatment slots. Providers also wanted to see an expansion of program services including indoor facilities, expanded hours of operation, and even home delivery. Included among the expansion of program services was the possibility of providing additional resources to exchange participants, possibly even enabling exchangers to develop a user-organized group (Moore \& Wenger, 1995). As Betty, a 41-year-old White woman said, "I would think that would be really something to think about, about having active users, I mean I think, it makes sense to me, you know." Finally, in order to better serve the exchangers, many providers believed that a training program would benefit their organization. Most providers said they did not receive any formal training prior to their 1st day in the field. Rather, they learned the ropes while in the field. Along with more support for the volunteers, training was repeatedly requested.

Many of the providers were conscious of the tension between maintaining their grassroots connections and seeking to expand and improve services. The street-based model was a good starting point, but some believed its limitations had started to affect their ability as an organization to reach some groups of people in need. Hannah, a 33-year-old White woman, explained that by diversifying, "we can start maybe reaching some people that we haven't yet reached with the street-based model." She saw the opportunity to create new relations with new clients but described it as "diversifying" beyond the street work, not replacing it.

The providers believed they needed more training about risk management, even though the tasks they performed had become routine for many of them. Ruth said she had never really thought about her personal risks until the organization began to provide training. The formal training process altered the meaning of risk taking for many volunteers.

I think there probably should be a series of training meetings. One thing that was very interesting was when they talked about the risk at the training, of needle sticks and all that. That had never crossed my mind that I was in any danger. I had thought of, maybe, physical danger, like when I went that day, I remember I didn't carry a lot of stuff with me because I thought, you know, who knows if the people are desperate or whatever.

Hannah also commented on the need for training and its importance to the growing organization. She said,

We need to have some way to recruit people, maybe even to screen people, to train people, to recognize the volunteers periodically. Things you see, I guess, in larger, more formalized organizations around maintaining the volunteer base. I think that would be for the good of the organization. 
The volunteers were conscious of the fact that new service providers would have to be brought in if the group was to expand its functions, and they wanted to provide the new volunteers with better organizational support and training than they themselves had received. Consistently, however, volunteers indicated that they remained committed to the group's participatory management style and even hoped to widen the distribution of authority and responsibility. For example, Christopher, a 33-year-old White man, believed strongly that it would be a good idea to involve active users in the management of the organization in order to maintain the integrity of ideological goals of integrating with the community in need. He explained,

There's been resistance to having users be involved, and you know I've been somebody who's advocated that over the years to have users more involved in this project. If you could get it to a point where the people who need the service are organizing the service, that would be better than providing the service to other people.

Christopher thought that volunteering to assist the clients of syringe exchange was a profound and important part of empowering them to help themselves. He elaborated,

There's nothing glamorous about drug use. It's not that much fun. You know, you feel bad about yourself and to have people who obviously care about you, enough to keep doing this thing, for free, I think that's been a positive message to our clients. But if we could create a system by which they could gradually take this project over so that they were really caring for themselves and for each other, that would be more politically empowering.

\section{CONCERNS ABOUT CO-OPTATION}

Volunteers generally wanted Prevention Point to become part of the public health care system, even if meant a partial loss of autonomy. Despite the personal excitement of underground work, volunteer providers also saw the legal restrictions under which they had operated as impediments to their larger goals. And although they saw the benefits in having protections against prosecution for those operating the exchange, they also measured the costs and benefits in terms of their participants and the larger social policy implications, including restrictions on the participation of clients in the group's management. As Sophia, a 22-year-old White woman, expressed it,

Okay, so Prevention Point can be legal and we can be allowed to exchange syringes, but as long as like the possession of paraphernalia is illegal for them, you know, it's almost like, well what's the point? What's 
the point in like trying to get ourselves legal if, you know, we're saying that we're protecting ourselves, we can hand these out, but you go down to the corner and you can get arrested for it. It kind of seems a bit pointless. Apart from the funding it kind of seems a bit pointless to do. I mean we should change our whole drug paraphernalia laws, you know.

The question of institutionalized funding elicited strong reactions from the providers we interviewed, both positive and negative. On the positive side, providers believed that funding would offer legitimacy to the program. Secure funding would also mean adequate supplies and the possibility of expansion of services. In addition, the changing nature of the organization offered the potential for increased organization and improved communication. Even though she did not really know much about the acquisition of provisions for the organization, Deborah, a 33-year-old White woman, felt the changes would be positive for stability. She said,

I don't know that much about how we get the needles anyway. I mean, I don't know, somebody shows up with them and I pass them out. I don't know where they come from, the big needle god in the sky or something. I think that what'll happen is there'll be some more structure to it, and it'll be more of a recognized institution or whatever, it's not some bunch of weirdos getting together and passing out needles, it's more of, it actually has funding, it's being recognized, it's a more serious kind of a thing rather than just some kind of loose thing.

In addition to guaranteeing adequate supplies, Deborah thought the changing structure would benefit the organization by formalizing in other ways:

I think that there should be some kind of a structure, and I think that the city should help. Because there is the money, it should be allocated for something like this. I guess somebody that has been volunteering there for a long time got one of the paid positions, or maybe all the people, I don't know about the other positions, but I think it's good that there are people that are going to be recognized and paid for what they've been doing, I think it's cool.

For some, the direct involvement of city and state agencies in syringe exchange also offered an opportunity for activists to seek influence in the health policy arena, to effect change from below. Ruth hoped that the organization's style and values would affect the state's bureaucracy rather than the other way around:

But, I would say that, even if needle exchange does become completely legal, and sanctioned by the state and all that, I think there still might be a 
role for the organizing staff definitely as advisors and policy setters if the government would let them do that. They accumulated a lot of wisdom.

However, the negative responses to the changing organizational structure were just as strong. Although some providers believed the stress associated with the changes was just "growing pains," others believed the changes would lead to negative consequences such as increased bureaucracy, a loss of organizational autonomy, and an emphasis on their less political, serviceoriented functions. They saw formalization as a severe blow to the organization's identity. Such anger at the growing bureaucracy came mostly from the long-term providers who continued to adhere to the original goals of Prevention Point, which were centered on a nonhierarchical model of leadership. A related fear was that new restrictions would become attached to the provision of clean needles. Sophia summarized many of the volunteers' feelings:

I worry that once you've got official funding from whatever governmental source for something, that it can, not necessarily, but it can carry so many strings attached, that I wonder if over time there'll be more of an attempt to like move Prevention Point completely off the streets, maybe into a shop front, or maybe further away from the hotels. I get really suspicious of why they are funding it. It's like, if you're saying, like up until now it's been illegal, but we're letting you basically do what you want, and still with some conditions, but not conditions that can be really strictly enforced because we're pretending you're not really there anyway. But once we're like recognizing you and saying okay, here's your funding, I think there's the potential to control the activities a lot more.

For the volunteers who had been less involved in running the organization there was less trepidation about the group's new formality. Although most of the providers expressed their desire to simply avoid the larger political struggles of syringe exchange, a few expressed interest in the development of the new structure and the formal organization meetings. For example, Ruth said,

I guess it makes me curious. How did it transform into an organization that has a paid full-time executive director position, and I don't know how many other people are paid, but, I'm kind of curious how it transformed itself into that. And there seem to be several people who were involved, you know, forever, in the beginning, so it just makes me curious about them and the transition.

\section{KEY ELEMENTS IN THE TRANSITION}

In most cases, the improvements identified by volunteers anticipated the pattern of changes that come with routinization: organizational formalization and division of labor (regular jobs, training); greater institutional connections 
(supplies, interorganizational linkages); professionalization (offices, increased hours, increased services); and routine participation in their organizational field, in this case the public health field. In each of these instances, Prevention Point's transition adhered closely to the ideal-typical pattern of organizational routinization (Rucht, 1999). In most of these areas as well, the volunteer staff favored the changes, at least in theory, based on the expectation that they would improve the organization's ability to serve its existing mission of harm reduction.

At the same time, volunteers hoped for many improvements that are generally perceived as inconsistent with routinization. None of those changes were adopted, confirming the apprehensions expressed by a number of early volunteers. Among the unfulfilled hopes were the informants' desires to better integrate their work into the communities of affected people and to better utilize past and current drug users in the organization. These goals were linked to the desire to improve their advocacy functions, which were perceived as integral to their mission. Informants linked the organization's participant management style with the ideological goal of providing the volunteers with a voice in their work, and beyond. Extending this model somewhat, many volunteers had hoped to include the exchange's participants in the new management structure, rooting the organization more deeply in the community on whose behalf they operated. Several of the former volunteers who were no longer at Prevention Point raised this issue as a particular disappointment, and a criticism of the professionalization of the program.

In response to questions about improving their work and their organization, many volunteers identified changes that they wished to see taking place at the state and city level. The one request that united all other wish-list items for the providers was that the state of California would change the laws regarding possession of paraphernalia. To some extent, this wish was granted, although it would be impossible to assess the role of Prevention Point in bringing about changes outside of their area of work. Volunteers further expressed the hope that Prevention Point could become more deeply embedded in its institutional and political environment, and that this environment would foster the growth of the organization's social and ideological goals. Again, in a limited fashion, they have achieved this change in their institutional location. Yet, many of the same sources who had hoped for greater institutional embeddedness had also hoped for greater community involvement in the organizational structure. In the end, the group moved toward the former and away from the latter.

In sum, several factors emerged as key elements in the organizational transition and the impact on volunteer commitment. These include both pragmatic and ideational concerns, all of which volunteers had hoped to see strengthened. The pragmatic benefits were quickly made manifest. Volunteer commitment, however, relied on the ideational rewards such as participant management, personal responsibility to the needs of their constituents, and the unifying ideology of harm reduction. All of these factors affected the social 
psychology of the volunteers' identification with harm reduction and needle exchange. As these various rewards diminished, the volunteers' sense of belonging also waned.

Participant management kept enough people engaged in the organization to smooth the initial transition. Over time, however, the philosophy of group decision making appeared to suffer. This was one of the few areas in which volunteers had earlier expressed hopes and about which they explicitly articulated disappointment. By 1995, at the conclusion of our data collection, few volunteers had much say in the decision-making process. Several of our respondents indicated they did not really know how those in charge came to be in charge. The organizational complexity that developed along with the division in labor led to the eventual hierarchical nature of information sharing. The social roles of the providers were in constant flux as the organization expanded and formalized. Yet, even with the eventual dilution of the participant management structure, it was this interim structure that allowed the organization to transform into a legitimate one. Even without direct input into the group's decision making and with the loss of the group's deviant status, many volunteers continued with their participation, sometimes drifting in and out after the transformation.

The energy of grassroots organizing cannot be overemphasized for this organization. Part of the collective energy came from the inherent illegality of the organization. Volunteers were conspiring together under conditions of risk to address a problem that no one else would touch. As credibility grew and additional sources of support became available, individual commitment was less essential. Some volunteers lost interest. This transformation did not take place by accident. The organization guided the tolerance of the local community in deviance defining, just as they responded to the community when the need for services was identified. As the concerns about HIV mounted, the community "defined deviancy down" (Moynihan, 1993) to a level that allowed Prevention Point to expand, thereby making individual contributions less urgent and more interchangeable.

If the illegality helped to define the group bond, it was the harm-reduction ideology of that organization that solidified it. Second to the energy of already politically motivated individuals, commitment to the harm-reduction philosophy and syringe exchange drove their actions. Prevention Point had provided an organizational space in which volunteers could "enact" their identities as activists in the public health realm. The organization was unique in its focus on humanitarian issues and deep concern for drug users, a highly stigmatized population. This focus allowed them to create a cohesive group identity with moral and philosophical roots. Previous research has indicated that shared values and interests are important in recruiting and maintaining volunteer members (Booth \& Bisztray, 1970; Kanter, 1972; Torres et al., 1991). When the focus of the organization shifted, even as its mission remained the same, the value commitment of the volunteers was strained or spoiled. 


\section{CONCLUSION}

We began by describing Prevention Point and detailing the process of transformation from a deviant organization to a legal and publicly supported one. We then explored the providers' motives to volunteer and their commitment to the organization. Our qualitative interviews with Prevention Point volunteers before the transition shed light on the process of organization transformation. They allow a unique social-psychological analysis of identity processes in volunteerism.

The conditions under which Prevention Point was founded and operated during its early years encouraged a small group of highly committed individuals to share all of the risks and all of the effort to keep the group alive. The circumstances required the supporters to make a strong personal identification with the organization and its mission. This identification was reflected in the organization's management process and division of labor, which involved all of the exchangers equally in both decision making and day-to-day tasks. The legal status of the organization created significant obstacles to its mission, and the members worked collectively to overcome these obstacles.

The relative success of the organization brought about changes in its status. Many of the obstacles were thereby removed. In response, the group gradually reorganized, shifting its structures and procedures away from those associated with secret conspiracies toward the more familiar norms of a social service agency with public funding. The immediate observable result of this change was to solve many of the problems against which the volunteers had struggled for years. The secondary impact was to undermine the bases of cultural solidarity that had been built into the group. Formalization included regular job titles and the beginnings of stratification in the division of authority. Volunteers, no longer at risk on the streets, were merely doing an unpaid, if important, job while "staff" made the operational decisions. New volunteers were trained in specific tasks and left out of others. The information and decision-making loop became more closed, and even some long-time members were left out of it.

A tertiary adjustment also seems to have been forming during the time of our study. Some of the founding or long-time members of Prevention Point felt that the organization was allowing itself to be co-opted by its funders and supporters. Specifically, the organization began to view itself in terms similar to those that appealed to the city rather than as a channel for the empowerment of a disenfranchised population. Of particular concern to many members was the fact that the more professional management style of the organization, although helping their relations with the city, increased the distance between the group and its participants-the IDUs. Many of the founders had viewed themselves and their work as tightly connected to this population, the people for whom the group existed, and off the screen of the health services world. They had hoped that the new resource stream would allow them to 
support greater involvement of the participants and to give them the ability to redirect the work of the organization toward that community's needs. In fact, the opposite change occurred, much to the frustration of many of our respondents.

Our analysis is limited in several ways. The data were originally collected with a focus on the experience for the exchanger participants, not the providers. We have a less complete picture of the providers, but it is a start in understanding their motivation and commitment to the organization. Our data are further limited by the deeply political context of community-based work in San Francisco. That is, the political and volunteer environment in San Francisco is very intense. We cannot estimate the degree to which the processes we have studied rely on such conditions. Within these limitations, our findings document successful elements in keeping an organization alive.

Was the organizational transformation necessary for survival of Prevention Point? Were their goals reached? The changing organization structure did, in fact, have an impact on organizational effectiveness. Some of their main shortterm goals were consistent with routinization and formalization, such as wanting a stable source of supplies, increased ancillary and program services, and program training. The transformation was successful in meeting these needs. They also had some unusual goals, one of which was to include current users in the organizational structure. This was not consistent with the transition to a more formal organization. Active users have continued to be involved in informal ways and are consulted about organizational needs and goals, but the new structure has not given them a stable place in the decisionmaking process. Although some of our respondents viewed this mixed success in meeting members' goals as a natural result of organizational growth, others viewed it as the result of choices made by organizational elites. It is therefore unclear whether the organization followed a standard model of professionalization and routinization for the "usual" reasons (efficiency, consolidation of power, viability), or because managers with professional backgrounds believed that the standard model was inevitable. In either case, the formalization process clearly alienated some of the volunteers who had been ideologically committed to the ideas of participant management.

Although they did not successfully include former and current users in the formal structure, the organizers of Prevention Point did achieve many of their broader, long-term goals. For example, "against all odds," the founders and later members contributed to changes in popular perception and local law. Although needle- and syringe-exchange programs continue to be contested across the country, in a growing number of cities there are institutionalized organizations of harm reduction for IDUs. Formal civic and political organizations are often instrumental in nature, with the goal of changing (or maintaining) the social order. The organization transformation did not kill the social movement to reduce harm for IDUs; it institutionalized parts of it. We cannot fully evaluate whether the transformation was necessary, though we can point 
to the positive effects of formalizing. Even though some founders might disagree with the current structure of the organization, the fact that it moved forward in a climate of uncertainty reflects the impact of their efforts.

Notes

1. The study participants have been assigned pseudonyms to ensure confidentiality.

2. One author spent some time in the field; the others were not involved in participant observations.

3. Community health outreach workers began bleach distribution in the San Francisco Bay Area in 1986.

4. At the time of this writing, Prevention Point (HIV Prevention Project) operated 12 sessions every week.

\section{References}

Booth, A., Babchuk, N., \& Knox, A. B. (1968). Social stratification and membership in instrumentalexpressive voluntary associations. Sociological Quarterly, 9, 427-439.

Booth, A., \& Bisztray, G. (1970). Value orientations, member integration and participation in voluntary association activities. Administrative Science Quarterly, 15, 39-45.

Broadhead, R. S., Van Hulst, Y., \& Heckathorn, D. D. (1999). Termination of an established needle exchange: A study of claims and their impact. Social Problems, 46, 48-66.

Brown, M. P. (1997). Replacing citizenship: AIDS activism and radical democracy. New York: Guilford.

Cain, R. (1995). Community-based AIDS organizations and the state: Dilemmas of dependence. AIDS and Public Policy Journal, 10, 83-93.

Carroll, W., \& Ratner, R. S. (1996). Master framing and cross-movement networking in contemporary social movements. Sociological Quarterly, 37, 601-625.

Chambre, S. M. (1997). Civil society, differential resources, and organizational development: HIV / AIDS organizations in New York City, 1982-1992. Nonprofit and Voluntary Sector Quarterly, 36, 466-488.

Della Porta, D. (1988). Recruitment processes in clandestine political organizations: Italian leftwing terrorism. International Social Movements Research, 1, 155-169.

Des Jarlais, D. C. (1995). Harm reduction-A framework for incorporating science into drug policy. American Journal of Public Health, 85, 10-12.

Des Jarlais, D. C., Paone, D., Friedman, S. R., Peyser, N., \& Newman, R. G. (1995). Regulating controversial programs for unpopular people: Methadone maintenance and syringe exchange programs. American Journal of Public Health, 85, 1577-1584.

DiMaggio, P. J., \& Powell, W. W. (1983). The iron cage revisited: Institutional isomorphism and collective rationality in organizational fields. American Sociolocial Review, 48, 147-160.

Elbaz, G. (1992). The sociology of AIDS activism. The case of ACT UP/New York, 1987-1992. Unpubllished doctoral dissertation, City University of New York.

Gould, R. (1991). Multiple networks and mobilization in the Paris commune, 1871. American Sociolocial Review, 56, 716-729.

Inciardi, J. A., \& Harrison, L. D. (2000). Harm reduction: National and international perspectives. Thousand Oaks, CA: Sage.

Jenkins, J. C. (1998). Channeling social protest: Foundation patronage of contemporary social movements. In W. W. Powell \& E. S. Clemens (Eds.), Private action and the public good (pp. 206216). New Haven, CT: Yale University Press. 
Jepperson, R. L. (1991). Institutions, institutional effects, and institutionalism. In W. W. Powell \& P. J. Dimaggio (Eds.), The new institutionalism in organizational analysis (pp. 143-163). Chicago: University of Chicago Press.

Kanter, R. M. (1972). Commitment and community. Cambridge, MA: Harvard University Press.

Kelley, M.S. (1994, March). Sidewalk politics: The case of anti-abortion protestors and clinic defense workers. Paper presented at Eastern Sociological Society, Baltimore, MD.

Kelley, M. S., Murphy, S., \& Lune, H. (2001). A cultural impact of needle exchange: The role of safer injection mentors. Contemporary Drug Problems, 48, 485-506.

Kochems, L. M., Paone, D., Des Jarlais, D., Ness, I., Clark, J., \& Friedman, S. R. (1996). The transition from underground to legal syringe exchange: The New York City experience. AIDS Education and Prevention, 8, 471-489.

Lane, S. D., Lurie, P., Bowser, B., Kahn, J., \& Chen, D. (2000). The coming of age of needle exchange: A history through 1993. In J. A. Inciardi \& L. D. Harrison (Eds.), Harm reduction: National and international perspectives (pp. 47-68). Thousand Oaks, CA: Sage.

Lebon, N. (1996). Professionalization of women's health groups in Sao Paulo: The troublesome road towards organizational diversity. Organization, 3, 588-609.

Lune, H. (2002). Reclamation activism in anti-drug organizing in the USA. Social Movement Studies, $1,147-168$

Lune, H., \& Oberstein, H. (2001). Embedded systems: The case of HIV/AIDS nonprofit organizations in New York City. Voluntas, 12, 463-483.

McAdam, D. (1982). Political process and the development of Black insurgency, 1930-1970. Chicago: University of Chicago Press.

Moore, L. D., \& Wenger, L. D. (1995). The social context of needle exchange and user selforganization in San Francisco: Possibilities and pitfalls. Journal of Drug Issues, 25, 583-598.

Morgen, S. (1986). The dynamics of cooptation in a feminist health clinic. Social Science and Medicine, 23, 201-210.

Moynihan, D. P. (1993). Defining deviancy down. American Scholar, 62, 17-30.

Murphy, S., Kelley, M. S., \& Lune, H. (2004). The health benefits of secondary syringe exchange. Journal of Drug Issues, 34(2), 246-268.

Murphy, S., Wenger, L., \& Kelley, M. S. (1996). An ethnographic evaluation of San Francisco's needle exchange program (Report Number RO1 DA08322). Bethesda, MD: National Institute on Drug Abuse.

Rosenbaum, M., Washburn, A., Knight, K., Kelley, M. S., \& Irwin, J. (1996). Treatment as harm reduction, defunding as harm maximization: The case of methadone maintenance. Journal of Psychoactive Drugs, 28, 241-250.

Rothschild-Whitt, J. (1979). The collectivist organization: An alternative to rational-bureaucratic models. American Sociological Review, 44, 509-527.

Rucht, D. (1999). Linking organization and mobilization: Michels' iron law of oligarchy reconsidered. Mobilization, 4, 151-169.

Staggenborg, S. (1988). The consequences of professionalization and formalization in the prochoice movement. American Sociolocial Review, 53, 585-606.

Strike, C. J., Myers, T., \& Millson, M. (2002). Needle exchange: How the meanings ascribed to needles impact exchange practices and policies. AIDS Education and Prevention, 14, 126-137.

Syringe exchange programs-United States, 1994-1995. (1995). Morbidity and Mortality Weekly Report, 44, 684-685.

Thoits, P. A., \& Hewitt, L. N. (2001). Volunteer work and well-being. Journal of Health and Social Behavior, 42, 115-131.

Thomas, J. (1999). Everything about us is feminist: The significance of ideology in organizational change. Gender \& Society, 13, 101-119.

Torres, C., McIntosh, W. A., \& Zey, M. (1991). The effects of bureaucratization and commitment on resource mobilization in voluntary organizations. Sociological Spectrum, 1, 19-44.

Weber, M. (1978). Economy and society: An outline of interpretive sociology (G. Roth \& C. Wittich, Eds.). Berkeley: University of California Press. (Original work published 1922) 
Zald, M., \& McCarthy, J. (1987). Appendix: The trend of social movements in America: Professionalism and resource mobilization. In M. Zald \& J. McCarthy (Eds.), Social movements in an organizational society (pp. 337-391). New Brunswick, NJ: Transaction Books.

Margaret S. Kelley is an assistant professor at the University of Oklahoma. Her research, both quantitative and qualitative, has focused primarily on illicit drug users and the effectiveness of drug treatment. Other research interests include women and crime, sports and delinquency, and alcohol use on college campuses. A key theme in her work has been examining the interaction of drug users with both formal and informal organizations, and the subcultures and networks that develop around alcohol and illicit drug use.

Howard Lune is an assistant professor of sociology and the director of urban studies at William Paterson University of New Jersey. His research includes studies of collective organizing in response to HIV/AIDS in New York City, the cultural politics of needle-exchange programs, relations between states and the nonprofit sector, and the role of the city in the context of globalization.

Sheigla Murphy, Ph.D, director, Center for Substance Abuse Studies at the Institute for Scientific Analysis, is a medical sociologist who has been researching various types of illicit drug use, violence, and medical and drug treatment for more than 25 years. She has been the principal investigator of eight National Institute of Health grants. Dr. Murphy has published numerous articles in Addiction Research, the Journal of Psychoactive Drugs, Journal of Drug Issues, Contemporary Drug Problems, Qualitative Sociology, and Social Science and Medicine. She is the coauthor (with Dan Waldorf and Craig Reinarman) of Cocaine Changes: The Experience of Using and Quitting (Temple University Press, 1991). Her most recent book (with coauthor Marsha Rosenbaum) is Pregnant Women on Drugs: Combating Stereotypes and Stigma (Rutgers University Press, 1999). 